\title{
Observations of Convective Thermals with Weather Radar $\mathscr{A}$
}

\author{
VALERY MELNIKOV \\ Cooperative Institute for Mesoscale Meteorological Studies, University of Oklahoma, and \\ NOAA/OAR/National Severe Storms Laboratory, Norman, Oklahoma \\ DUSAN S. ZRNIĆ \\ NOAA/OAR/National Severe Storms Laboratory, Norman, Oklahoma
}

(Manuscript received 6 April 2017, in final form 18 May 2017)

\begin{abstract}
It is shown that the NEXRAD weather radar with enhanced detectability is capable of observing the evolution of convective thermals. The fields of radar differential reflectivity show that the upper parts of the thermals are observable due to Bragg scatter, whereas scattering from insects dominates in the lower parts. The thermal-top rise rate is between 1.5 and $3.7 \mathrm{~m} \mathrm{~s}^{-1}$ in the analyzed case. Radar observations of thermals also enable estimations of their maximum heights, horizontal sizes, and the turbulent dissipation rate within each thermal. These attributes characterize the intensity of convection.
\end{abstract}

\section{Introduction}

The primary uses of weather surveillance radars are to monitor severe weather and to measure precipitation (e.g., Doviak and Zrnić 2006). Some centimeterwavelength radars can also observe echoes from turbulent humid air due to Bragg scatter. This capability depends on the radar wavelength and sensitivity. Typically, Bragg scatter in clear air appears as layered echoes located at the top of the convective boundary layer (CBL; e.g., Doviak and Zrnić 2006, chapter 11; Heinselman et al. 2009; Melnikov et al. 2011, 2013; Richardson et al. 2017). CBL is a layer in which warm air bubbles, also known as thermals, form near the ground and rise. The sizes of thermals, their maximal heights, and top rise rates characterize the convective intensity (e.g., Stull 1988, chapter 11; Gossard and Strauch 1983) and can be used in forecasting of severe weather.

Convective thermals have been observed with vertical-pointing frequency-modulated continuous wave (FMCW) radars operating at a wavelength of $10 \mathrm{~cm}$

\footnotetext{
Supplemental information related to this paper is available at the Journals Online website: http://dx.doi.org/10.1175/JTECH-D17-0068.s1.
}

Corresponding author: Valery Melnikov, valery.melnikov@ noaa.gov (e.g., Gossard 1990; Doviak and Zrnić 2006, sections 11.6.1,11.7). The sources of echo were Bragg scatter and atmospheric insects. The thermals have also been observed with lidar at a horizontal distance up to $8 \mathrm{~km}$ (Hooper and Eloranta 1986; Crum et al. 1987) where atmospheric aerosol was the source of the echo.

The thermals typically contain flying insects that contribute to radar echoes and complicate the interpretation of data. Insects in thermals were observed by Gossard (1990) and Contreras and Frasier (2008) with FMCW S-band radar, Fabry and Zawadzki with verticalpointing X-band radar (Fabry 2015, p. 71), and Geerts and Miao (2005) with vertical-looking millimeterwavelength radar; the latter radar cannot detect Bragg scatter because of its short wavelength. Studying developing warm cumulus with S-band radar, Knight and Miller (1998) discussed possible contributions from insects. In severe weather situations, Wilson and Schreiber (1986) and Wilson et al. (1994) discussed Bragg scatter and insects as sources of radar echoes from the convergence lines and came to a conclusion that insects are the main source of radar echoes, although Bragg scatter was not excluded. All the abovementioned observations used nonpolarimetric radar data in which distinguishing Bragg from insect echoes in not possible.

Turbulent eddies with sizes of about 5 -cm scatter S-band radiation (e.g., Doviak and Zrnić 2006, section 11.6) and produce differential reflectivity $\left(Z_{\mathrm{DR}}\right)$ close to 
$0 \mathrm{~dB}$ (Melnikov et al. 2011). Values of $Z_{\mathrm{DR}}$ from insects are typically larger than $1 \mathrm{~dB}$ and can be several decibels (e.g., Zrnić and Ryzhkov 1998). This discriminating property has been successfully applied by Knight et al. (2002) to document the early history of $Z_{\mathrm{DR}}$ in Florida cumulus. Our study similarly uses $Z_{\mathrm{DR}}$ with the addition of the copolar correlation coefficient $\rho_{\mathrm{hv}}$ and the differential phase $\Phi_{\mathrm{DP}}$ to identify insects in convective thermals (section 2). Radar-derived properties of thermals are discussed in section 3. Bragg scatter at $\mathrm{S}$ band is typically weak. Special processing procedures to increase the detectability of weak echoes are discussed in the next section.

\section{Processing procedures to increase radar detectability}

We have conducted experiments with the S-band research KOUN Weather Surveillance Radar-1988 Doppler (WSR-88D) located in Norman, Oklahoma. To increase the detectability of weak echoes, a number of signal processing procedures have been implemented on the KOUN radar that allow for obtaining the radar moments at a signal-to-noise ratio (SNR) much lower than $2 \mathrm{~dB}$, which is typically used in operations. In short radar pulse $(1.57 \mu \mathrm{s})$ mode, 256 samples from a single radar resolution volume have been used to calculate the radar variables at a pulse repetition frequency of $1000 \mathrm{~Hz}$. Returns were oversampled in range and elevation angle by a factor of 5 . Because the length of the short pulse is $250 \mathrm{~m}$, oversampling in range produces voltage samples every $50 \mathrm{~m}$. Oversampling in elevation angle means obtaining the radar variables in elevation at a spacing of $1 \%=0.2^{\circ}$. The two-dimensional despeckling procedure described by Melnikov and Schlatter (2011) has been applied to the fields of radar variables. The $Z_{\mathrm{DR}}$ values have been calculated using the lag-1 algorithm (Melnikov and Zrnić 2007) to eliminate noise bias. These procedures enabled observations of the radar fields at SNR $=-7 \mathrm{~dB}$, that is, $9 \mathrm{~dB}$ lower than the operationally used SNR threshold. We have collected radar data in elevation scans [range-height indicator (RHI)] at a constant azimuth and up to $30^{\circ}$ of the antenna elevation angle. The radar update time in a single RHI was about $1 \mathrm{~min}$; this includes the quick downward antenna motion during which data are not useful because of the high antenna descent rate.

Figure 1 demonstrates the enhanced detectability of weak radar echoes. Figure 1a presents an RHI of reflectivity obtained at $\mathrm{SNR} \geq 2 \mathrm{~dB}$ (the operational default SNR). Note that this field cannot be obtained using operational parameters because 256 samples and oversampling are not currently in use. Figure $1 \mathrm{~b}$ presents the $Z$ field at SNR $\geq-7 \mathrm{~dB}$; clearly the echo extends over a much larger areas than in Fig. 1a. Two enhanced layers are seen in Fig. 1b: the lower one tops at about $2-2.5 \mathrm{~km}$ and the second one at an altitude of about $4 \mathrm{~km}$. One more layer of weak reflectivity is seen at a height of about $3 \mathrm{~km}$. Figures $1 \mathrm{~d}$ and $1 \mathrm{e}$ show $Z_{\mathrm{DR}}$ fields generated at $\mathrm{SNR} \geq 2 \mathrm{~dB}$ (Fig. 1d) and SNR $\geq-7 \mathrm{~dB}$ (Fig. 1e). The echo in Fig. 1d has a smaller extent than that in Fig. 1a because the 2-dB SNR threshold has been applied to signals in the horizontal and vertical channels separately. The vertical channel has weaker signals than that in the horizontal channel because $Z_{\mathrm{DR}}$ in the upper layer is $4-5 \mathrm{~dB}$ (Fig. 1e). In Fig. 1e the echo extent is larger, demonstrating the enhanced detectability.

The upper layer of the radar echo lies in temperatures exceeding $0^{\circ} \mathrm{C}$ and has a $Z_{\mathrm{DR}}$ of $4-6 \mathrm{~dB}$, signifying that insects are present (the temperature profiles can be found in Fig. S1). The lower layer in Fig. 1e exhibits a clear pattern: its bottom part up to $1.0-1.5-\mathrm{km}$ height has $Z_{\mathrm{DR}}$ values $>9 \mathrm{~dB}$ and the top part, which is in a form of plumes, has $Z_{\mathrm{DR}}$ values $<1 \mathrm{~dB}$. Scattering from insects dominate in the lower part, whereas the upper part is mainly from Bragg scatter $\left(Z_{\mathrm{DR}}\right.$ values are near $\left.0 \mathrm{~dB}\right)$, although in some areas a small number of insects appear to increase $Z_{\mathrm{DR}}$ up to $1 \mathrm{~dB}$. The correlation coefficients in the upper part of the lower layer are high (Fig. $1 \mathrm{f}$ ) and the differential phase is equal to the system differential phase (Fig. 1c). These two properties also point to Bragg scatter as a primary source in the upper part of the lower echo (Melnikov et al. 2011). The whole lower echo layer has a plume pattern indicative of its convective nature. The polarization radar capability allows for discriminating parts of the thermals filled with insects and parts in which Bragg scatter prevails.

The ground clutter filter suppressed some echo within $30 \mathrm{~km}$ from the radar that can be seen as white gaps in the data near the ground. The filter was applied at all antenna elevations to suppress clutter contaminations caused by the antenna sidelobes. One can see quasi-vertical white strips (for instance, at a distance of about $25 \mathrm{~km}$ ) caused by the filter.

\section{Properties of the observed thermals}

The radar continuously collected data in the described mode on 19 July 2013. An animation of $Z_{\mathrm{DR}}$ images can be found in the supplemental materials. No precipitation was observed on that day in central Oklahoma. At about 1600 UTC, the first convective thermals were detected by the radar. At about 1730 UTC, lowlevel cumulus clouds began to develop, but they did not grow to precipitating clouds (Fig. S4). 

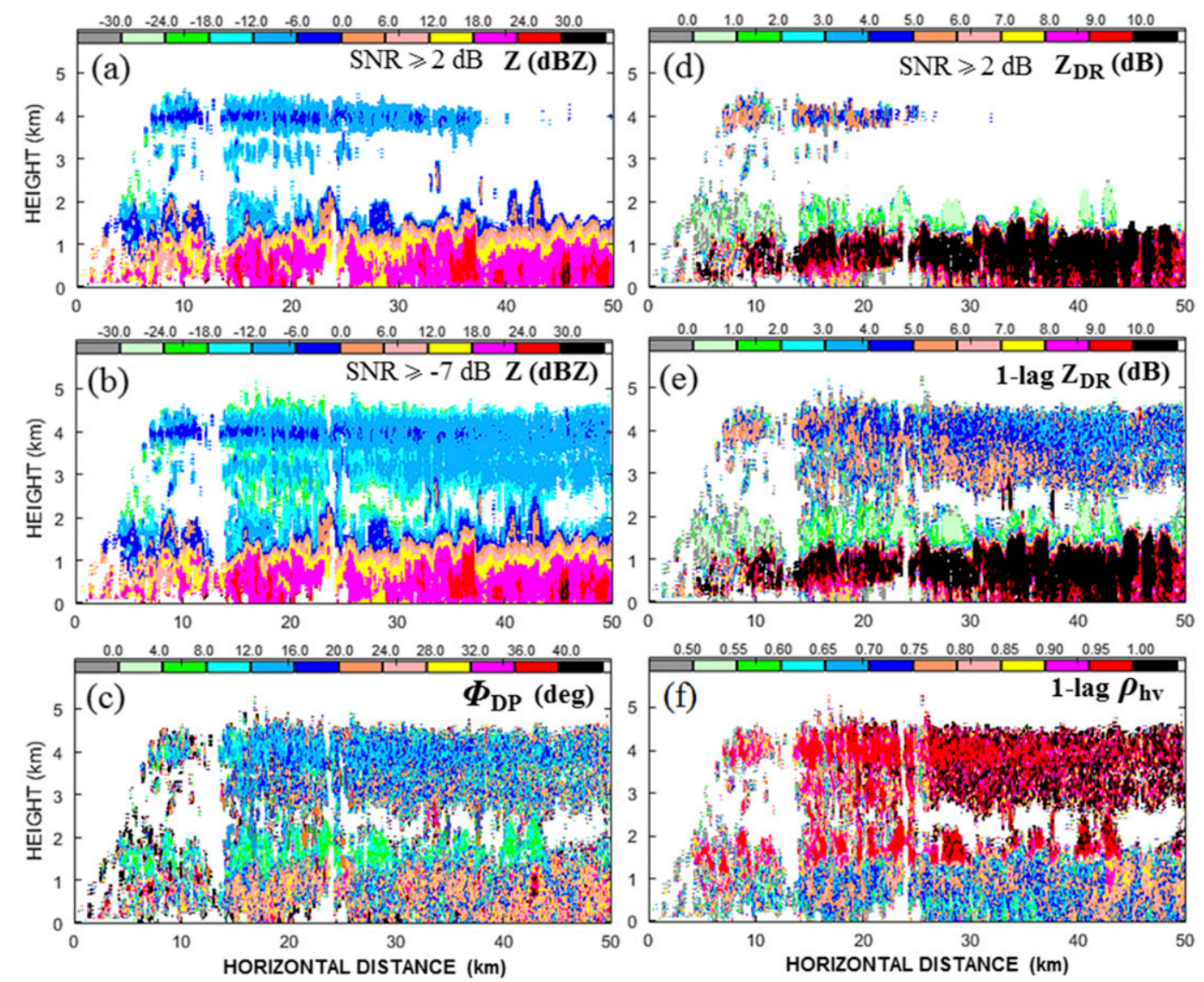

FIG. 1. Vertical cross sections obtained with KOUN at 1800 UTC 18 Jul 2013 at an azimuth of $191^{\circ}$. Local time is $6 \mathrm{~h}$ earlier than the indicated UTC stamps.

The intensity of convection can be estimated by observing the rise rate of the thermals' tops where $Z_{\mathrm{DR}}$ is close to $0 \mathrm{~dB}$. For that, the radar RHI plane should be oriented along the wind to minimize crossbeam advection impacts (i.e., movement of thermals across the plane of the RHI) and the radar update time should be short enough to observe continuity in the evolution of convective plumes. In our experiments, the azimuth of RHI was set to $191^{\circ}$ because this was close to the wind direction near the ground and at an altitude of about $2.5 \mathrm{~km}$ at 0000 UTC 19 July 2013 (Fig. S1a). The update time of a single RHI was $67 \mathrm{~s}$. The time stamps in the $Z$ frames (Fig. 2) correspond to the beginning of the scans when the radar beam was horizontal. The update time is sufficiently short to observe the life circle of the thermals' tops (Fig. 2). The tops of plumes were obtained from a two-dimensional $Z$ field having a step of $50 \mathrm{~m}$ in the distance and height directions because of 50-m sampling of radar data along the radar radial. So, the accuracy of obtaining the top of a plume is $50 \mathrm{~m}$. First, a distinct thermal was identified in its mature stage: one can see a strong plume at about $38 \mathrm{~km}$ from the radar at 1802:15 UTC.
This thermal is marked with a vertical arrow in the $Z_{\mathrm{DR}}$ field. Tracking this plume back in time, we found that at 1756:39 UTC it could barely be identified above the mean top of the convective thermal. Tracking the plume forward, we found that the plume stopped growing at 1804:30 UTC. After this time the thermal's top was at its maximal height of about $4.2 \mathrm{~km}$ for several minutes (Fig. S2). In $471 \mathrm{~s}$, the thermal's top grew $1370 \mathrm{~m}$, so its rise rate was $2.9 \mathrm{~m} \mathrm{~s}^{-1}$. We have applied the described estimation of the thermal-top rise rate to several plumes observed on that day and obtained the rate in the interval $1.5-3.7 \mathrm{~m} \mathrm{~s}^{-1}$. An example is in Fig. S3, where four thermals are denoted with numbered vertical arrows. Plumes 1-4 had the grow rates 3.7, 2.2, 2.0, and $1.9 \mathrm{~m} \mathrm{~s}^{-1}$, respectively. These rates obtained from a single RHI plane are estimates because the horizontal winds can change its direction with height, and crossbeam advection can influence the top-raise rate. To minimize the advection impact, RHIs in a few close directions or a number of PPIs (slant near horizontal sweeps) in a sector could be made. Such scanning could be done with a phased array radar with signal processing and methodology described here. 

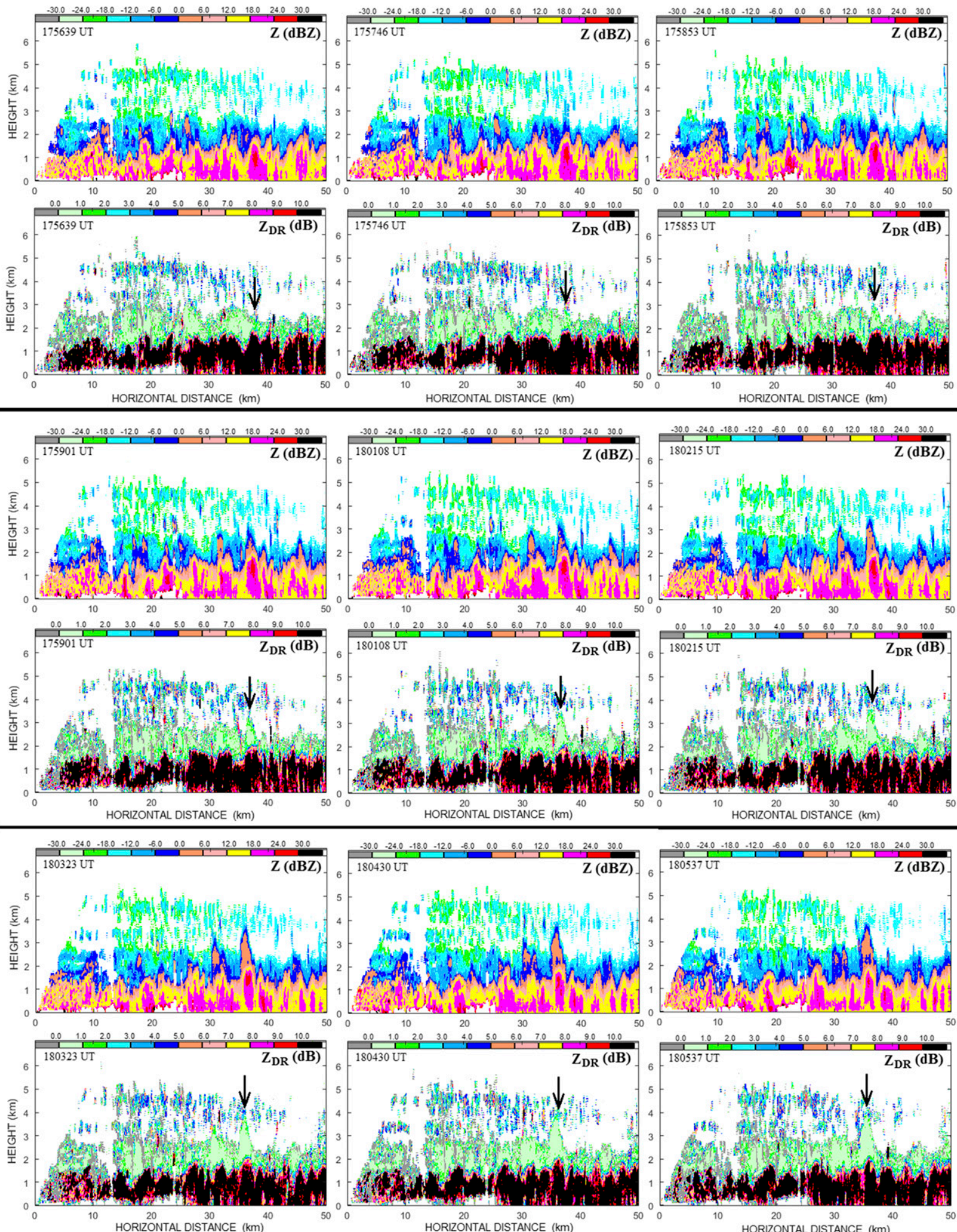

FIG. 2. Vertical cross sections of $Z$ and $Z_{\mathrm{DR}}$ collected with WSR-88D KOUN at an azimuth of $191^{\circ}$ from 1756:39 to $1805: 37$ UTC $19 \mathrm{Jul} 2013$. 
A sharp gradient in the $Z_{\mathrm{DR}}$ field (Fig. 2) is striking. The top of echoes with large $Z_{\mathrm{DR}}$ values is at a height of about $1.5 \mathrm{~km}$. There is no doubt insects fill this layer because only they can produce such large $Z_{\mathrm{DR}}$ over an extended range near the ground. The mean top of thermals with low $Z_{\mathrm{DR}}$ values is at an altitude of about $3 \mathrm{~km}$. Some strong thermals propagate to a height of $4.2 \mathrm{~km}$, indicating that both mean and maximal heights of convective thermals can be readily observed.

The horizontal dimensions of thermals can also be estimated from radar echoes. One can see that the thermals in Fig. 2 have a variety of widths. The structure exhibits various widths, which are more pronounced in the $Z$ field than in the $Z_{\mathrm{DR}}$ field. The following hypothesis offers an explanation. Assuming that the same insects are present throughout the field, their concentration is changed by the converging/diverging air near ground and by the resistance of insects to being carried aloft (Wilson et al. 1994; Drake and Reynolds 2012, chapters 13 and 15). This does not affect $Z_{\mathrm{DR}}$ because it is not sensitive to concentration but only the shape of insects, whereas it does affect $Z$. Note that some plumes consist of two or three close thermals seen in the $Z$ field. The widths of thermals obtained from the $Z$ field at a height of $0.5 \mathrm{~km}$ are from 1 to $3 \mathrm{~km}$.

Echoes from clear air are caused by turbulent fluctuations of temperature and humidity that define the value of the refractive index structure parameter $C_{n}^{2}$, which can be used for estimating the intensity of turbulence. The upper part of the thermal with $Z_{\mathrm{DR}}$ close to $0 \mathrm{~dB}$ is predominantly caused by Bragg scatter. The term $C_{n}^{2}\left(\mathrm{~m}^{-2 / 3}\right)$ can be estimated from measured reflectivity $Z(\mathrm{~dB} Z)$ as $\log _{10} C_{n}^{2}=0.1$ $Z$ (dBZ) - 11.6 (Melnikov et al. 2011). The $Z$ values in the upper parts of the thermals lie in the interval -10 to $5 \mathrm{dBZ}$, which corresponds to the interval $2.5 \times 10^{-13}-7.9 \times$ $10^{-12} \mathrm{~m}^{-2 / 3}$ of $C_{n}^{2}$. This is within the range reported by Rabin and Doviak (1989) from observations in a similar Oklahoma air mass. Structure parameter $C_{n}^{2}$ shows the intensity of turbulence and can be used in forecasting the development of precipitating clouds. These estimations of $C_{n}^{2}$ have been made assuming no contribution to $Z$ from cloud droplets. The WSR-88D is sensitive enough to observe large cloud droplets (Gossard 1990). The presence of such droplets in the analyzed case is questionable; therefore, the abovementioned estimates of $C_{n}^{2}$ should be taking cautiously. To resolve this uncertainty, simultaneous measurements at two wavelengths could be utilized: one at $\mathrm{S}$ frequency band and the other at a millimeter wavelength (a cloud radar) insensitive to Bragg scatter.

\section{Conclusions}

Increased radar detectability, polarization capability, and rapid data update make possible observations of convective thermals and their temporal and spatial evolutions. Enhancements in radar detectability have been achieved by applying the lag- 1 estimators of radar variables and a two-dimensional speckle removal to the fields of polarimetric variables. The detection of thermals is further enhanced by about a 4-times longer dwell time and a fivefold oversampling in both range and elevation angle compared to regular WSR-88D observations. Nonetheless, powerful polarimetric spectral processing techniques alone might offer several decibels of increased sensitivity. These can be combined with despeckling as done here and/or consensus procedures similar to the one used on the wind profiling radars. We expect that these would further improve detection of weak echoes, or might match the detection presented here but with shorter dwell times that would increase the practical appeal. Further exploration of these alternatives is in order.

The polarization radar capability distinguishes the lower part of each thermal containing insects (with large $Z_{\mathrm{DR}}$ values) from the upper parts, which has many fewer insects or is entirely free from insects (with $Z_{\mathrm{DR}}$ close to $0 \mathrm{~dB}$ ). A radar update time of about $1 \mathrm{~min}$ is sufficiently short to observe developing thermals and to estimate their horizontal sizes $(1-3 \mathrm{~km}$ at a height of $0.5 \mathrm{~km}$ in the analyzed case), the rise rates of the tops $\left(1.5-3.7 \mathrm{~m} \mathrm{~s}^{-1}\right)$, and heights $(2-4 \mathrm{~km})$. The mean top of the convective boundary layer during the most intense convection was at a height of $3 \mathrm{~km}$, but some thermals achieved an altitude of $4.2 \mathrm{~km}$. The refractive index structure parameter $C_{n}^{2}$ in the thermals was within the interval $2.5 \times 10^{-13}-7.9 \times$ $10^{-12} \mathrm{~m}^{-2 / 3}$ in the upper portions of the thermals. These characteristics are important properties of convection, which could be used in forecasting of severe weather.

We collected data from vertical cross sections at a single azimuth, which were aligned close to the wind direction so that we could observe the growth of thermals, but there may still have been some minor advection. Since the wind direction can change with height and time, radar observations in several close azimuths at an update time of about $1 \mathrm{~min}$ are desired to accurately observe the tops of thermals. This is a challenging request for radar with a mechanical dish antenna, but such a scanning strategy is possible with phased array radar, provided its sensitivity matches or exceeds that of the WSR-88D. If this technological challenge can be overcome, we envision a possibility of identifying in real time the specific areas of enhanced potential for convective storms (i.e., deep moist convection) initiation. We hypothesize the likelihood of storm initiation is enhanced in the areas of most intense thermals. Assimilating the parameters of such thermals into numerical models might significantly improve the specificity of forecasts. 
Acknowledgments. We thank Alexander Ryzhkov and Jeffrey Snyder for the discussions. Funding for this study was provided in part by the NOAA/Office of Oceanic and Atmospheric Research under NOAAUniversity of Oklahoma Cooperative Agreement NA17RJ1227, U.S. Department of Commerce.

\section{REFERENCES}

Contreras, R. F., and S. J. Frasier, 2008: High-resolution observations of insects in the atmospheric boundary layer. J. Atmos. Oceanic Technol., 25, 2176-2187, doi:10.1175/ 2008JTECHA1059.1.

Crum, T. D., R. B. Stull, and E. W. Eloranta, 1987: Coincident lidar and aircraft observations of entrainment into thermal and mixed layers. J. Appl. Meteor. Climatol., 26, 774-788, doi:10.1175/1520-0450(1987)026<0774:CLAAOO>2.0.CO;2.

Doviak, R. J., and D. S. Zrnić, 2006: Doppler Radar and Weather Observations. 2nd ed. Dover Publications, $562 \mathrm{pp}$.

Drake, V. A., and D. R. Reynolds, 2012: Radar Entomology: Observing Insect Flight and Migration. CABI, 489 pp.

Fabry, F., 2015: Radar Meteorology: Principles and Applications. Cambridge University Press, $256 \mathrm{pp}$.

Geerts, B., and Q. Miao, 2005: The use of millimeter Doppler radar echoes to estimate vertical air velocities in the fair-weather convective boundary layer. J. Atmos. Oceanic Technol., 22, 225-246, doi:10.1175/JTECH1699.1.

Gossard, E. E., 1990: Radar research on the atmospheric boundary layer. Radar in Meteorology: Battan Memorial and 40th Anniversary Radar Meteorology Conference, D. Atlas, Ed., Amer. Meteor. Soc., 477- 527.

— , and R. G. Strauch, 1983: Radar Observations of Clear Air and Clouds. Elsevier, 280 pp.

Heinselman, P. L., D. J. Stensrud, R. M. Hluchan, P. L. Spencer, P. C. Burke, and K. L. Elmore, 2009: Radar reflectivity-based estimates of mixed layer depth. J. Atmos. Oceanic Technol., 26, 229-239, doi:10.1175/2008JTECHA1091.1.

Hooper, W. P., and E. W. Eloranta, 1986: Lidar measurements of wind in the planetary boundary layer: The method, accuracy and results from joint measurements with radiosonde and kytoon. J. Climate Appl. Meteor., 25, 990-1001, doi:10.1175/ 1520-0450(1986)025<0990:LMOWIT > 2.0.CO;2.

Knight, C. A., and L. J. Miller, 1998: Early radar echoes from small, warm cumulus: Bragg and hydrometeor scattering. J. Atmos.
Sci., 55, 2974-2992, doi:10.1175/1520-0469(1998)055<2974: EREFSW $>2.0 . \mathrm{CO} ; 2$.

— J. Vivekanandan, and S. G. Lasher-Trapp, 2002: First radar echoes and the early $Z_{\mathrm{DR}}$ history of Florida cumulus. J. Atmos. Sci., 59, 1454-1472, doi:10.1175/1520-0469(2002)059<1454: FREATE $>2.0 . \mathrm{CO}$; .

Melnikov, V. M., and D. S. Zrnić, 2007: Autocorrelation and cross-correlation estimators of polarimetric variables. J. Atmos. Oceanic Technol., 24, 1337-1350, doi:10.1175/ JTECH2054.1.

— larimetric WSR-88D. 27th Conf. on Interactive Information Processing Systems (IIPS), Seattle, WA, Amer. Meteor. Soc., 14.3. [Available online at https://ams.confex.com/ams/ 91Annual/webprogram/Paper178856.html.]

—, R. J. Doviak, D. S. Zrnić, and D. J. Stensrud, 2011: Mapping Bragg scatter with a polarimetric WSR-88D. J. Atmos. Oceanic Technol., 28, 1273-1285, doi:10.1175/ JTECH-D-10-05048.1.

,,--- , and,- 2013 : Structures of Bragg scatter observed with the polarimetric WSR-88D. J. Atmos. Oceanic Technol., 30, 1253-1258, doi:10.1175/JTECH-D-12-00210.1.

Rabin, R., and R. J. Doviak, 1989: Meteorological and astronomical influences on radar reflectivity in the convective boundary layer. J. Appl. Meteor., 28, 1226-1235, doi:10.1175/ 1520-0450(1989)028<1226:MAAIOR > 2.0.CO;2.

Richardson, L. M., J. G. Cunningham, W. D. Zittel, R. R. Lee, R. L. Ice, V. M. Melnikov, N. P. Hoban, and J. G. Gebauer, 2017: Bragg scatter detection by the WSR-88D. Part I: Algorithm development. J. Atmos. Oceanic Technol., 34, 465-478, doi:10.1175/ JTECH-D-16-0030.1.

Stull, R. B., 1988: An Introduction to Boundary Layer Meteorology. Kluwer Academic, 666 pp.

Wilson, J. W., and W. E. Schreiber, 1986: Initiation of convective storms at radar-observed boundary-layer convergence lines. Mon. Wea. Rev., 114, 2516-2536, doi:10.1175/ 1520-0493(1986)114<2516:IOCSAR > 2.0.CO;2.

_- , T. M. Weckwerth, J. Vivekanandan, R. M. Wakimoto, and R. W. Russell, 1994: Boundary layer clear-air radar echoes: Origin of echoes and accuracy of deriving winds. J. Atmos. Oceanic Technol., 11, 1184-1206, doi:10.1175/ 1520-0426(1994)011<1184:BLCARE > 2.0.CO;2.

Zrnić, D. S., and A. V. Ryzhkov, 1998: Observations of insects and birds with a polarimetric radar. IEEE Trans. Geosci. Remote Sens., 36, 661-668, doi:10.1109/36.662746. 